\title{
Intercusp differences in enamel prism patterns in early and late stages of human tooth development
}

\author{
Tania Zeygerson, Patricia Smith, Rebeca Haydenblit* \\ Laboratory of BioAnthropology and Ancient DNA, The Hebrew University-Hadassah, School of Dental Medicine, \\ Jerusalem 91120, Israel
}

Accepted 19 April 2000

\begin{abstract}
Enamel prism-packing patterns reflect the past history of ameloblasts, providing information about growth patterns in tooth development. Here, the area and density of enamel prisms on the cuspal surface of molar teeth were measured to examine if the onset and rate of enamel apposition differ according to stage of development and/or cusp type. Scanning electron-microscopic images were taken from the mesiobuccal and distal cusp tips of 30 mandibular first permanent molars at different stages of development recovered from archaeological sites in Israel dating to the past 10000 years. Selected enamel microstructural characters were measured for each cusp. The mean area of prisms on the mesiobuccal (MB) cusp was significantly larger than that of the distal (D) cusp at all stages of development and the differences in prism area between cusps were significant for each stage of development. Prism density was significantly smaller on the MB cusp than the D cusp at all stages of development but no significant differences were found between early and later stages in each cusp. This was interpreted as indicating that enamel formation in the MB cusp was almost complete, even in the earliest tooth germs studied, whereas in the D cusp it was less advanced. The differences between $\mathrm{MB}$ and $\mathrm{D}$ cusps are proposed to result from asynchrony of enamel formation between the different cusps of molar teeth in recent populations. The method provides a non-destructive approach to the study of growth patterns in teeth and provides baseline data for comparison with fossil teeth. (C) 2000 Elsevier Science Ltd. All rights reserved.
\end{abstract}

Keywords: Crown formation; Enamel apposition; Enamel prisms; Growth patterns

\section{Introduction}

Tooth formation is the end result of a long developmental process involving interactions between oral epithelium and cranial, neural crest-derived ectomesenchyme (Thesleff and Hurmerinta, 1981; Kollar, 1983; Ruch, 1984). The timing, rate and duration of these events vary along the tooth row and are believed

\footnotetext{
* Corresponding author. Tel.: + 972-2-6757608; fax: +9722-6757451.

E-mail address: haydenbl@cc.huji.ac.il (R. Haydenblit).
}

to determine the final tooth size and form (Butler, 1956; Slavkin, 1990).

Teeth are covered by enamel, which is the most highly mineralised tissue formed in mammalian biological systems. Enamel has two important properties, durability and structural complexity; because of its durability, teeth are preferentially preserved in the fossil record and its microstructural complexity contains information on growth patterns and development (Risnes, 1998; Shellis, 1998).

Enamel formation and the final size and shape of teeth are studied in two main ways: by measurement of enamel thickness and by examination of the morphol- 
ogy of the dentine, which underlies the enamel cap. The tooth crown forms incrementally, with striae representing isochronous secretory fronts and prism cross-striations representing daily increments (Beynon and Dean, 1988; Beynon et al., 1991; Dean and Beynon, 1991). Previous studies have used microstructural characteristics, particularly enamel prism shape, to distinguish variations between modern and extinct primates (Boyde, 1990; Boyde and Martin, 1982, 1984).

Prism orientation appears to vary with the overall morphology of the dentine-enamel junction and total enamel thickness (Shellis, 1984; Stern and Skobe, 1985; Osborn, 1990; Maas, 1991). Moreover, the pattern of growth of deciduous and permanent modern teeth differs (Shellis, 1984). Calculations of prism size and spacing in human dentitions show that the number and density of ameloblasts is different between deciduous and permanent teeth (Shellis, 1984). It appears that deciduous teeth grow faster than permanent teeth but have smaller, less densely arranged enamel prisms (Shellis, 1984). This rapid pattern of growth is also seen in fossil teeth (Bromage and Dean, 1985; Beynon and Wood, 1986; Dean et al., 1986; Beynon and Dean, 1987; Ramirez Rozzi, 1993; Smith, 1991; Smith et al., 1997).

There are differences in crown shape, enamel thickness, and the incremental manner of crown formation among molars within humans (Reid et al., 1998; Risnes, 1998). A recent study has given a clear reconstruction of how modern humans differ in some aspects of their tooth development (Reid et al., 1998). Crown formation time varied between 3.39 years for the first mandibular permanent molar and 3.16 years for the second mandibular permanent molar. This study shows how different cusps grow at different rates in one individual in both maxillary and mandibular molars. Furthermore, crown formation is initiated in the second molar before the conclusion of enamel formation in the first molar of the same individual (Reid et al., 1998).

Our purpose now is to examine selected microstructural characteristics and particularly the arrangement at the occlusal surface of distinct regions in developing modern human permanent teeth in order to explore the relation between mechanisms and rates of crown formation and changes in the final tooth size and shape.

\section{Materials and methods}

Scanning electron-microscopic images were taken on first permanent lower tooth germs of different stages of development, starting from the stage of five mineralised cusps to the beginning of the formation of the tooth root. Thirty tooth germs were carefully removed from the crypts of archaeological specimens from Israel dating to the past 10000 years. Teeth were gently cleaned with acetone and a fine brush. None of the teeth had any observable wear facets, caries, cracks or other postmortem damage. Sex of the archaeological specimens was unknown. The maximum mesiodistal length (MD) and buccal crown height $(\mathrm{BCH})$ were measured with specially sharpened Mitutoyo electronic sliding calipers accurate to $0.1 \mathrm{~mm}$. The mesiodistal measurement was taken along the maximal diameter of the tooth along its mesiodistal axis, and the buccal crown height measurement was taken at the right angle to the mesiodistal axis from the tip of the mesiobuccal cusp to the lowest margin of the developing crown. Ten teeth were remeasured to check the error of measurement and this was found to average $2 \%$.

Tooth germs were placed in 5\% hydrochloric acid for $10 \mathrm{~s}$ as described by Maas (1991); this caused some surface demineralisation and provided better definition of the enamel prisms. The teeth were then rinsed in distilled water overnight and dried in air. They were then stuck on stubs and coated with gold in the E51000 coating unit at $20 \mathrm{~mA}$ for $2-3 \mathrm{~min}$. Teeth were then transferred to a Phillips SEM 505 with an accelerating voltage of $20 \mathrm{kV}$. A magnification of $\times 20$ was used to locate the appropriate cuspal surface area and orientate it such that the cuspal plane was $90^{\circ}$ to the beam and focused approximately half way between the base and tip of the cusp. In order to assess the correct position of the image, the specimen and more precisely the pre-specified location on the slope of the cusp, was rotated until it reached the camera at right angles to the surface. We also tested for replicability of measurements through repositioning, rephotographing and remeasuring the samples. Photographs were then taken at magnifications of $\times 20, \times 50$ and $\times 2500$. In order to estimate the possible variation introduced through poor orientation, the first two photographs were used to record the precise location of the selected field of examination and the $\times 2500$ magnification was used to measure prism area.

Prism area (PA) was measured as follows: the boundaries of five randomly selected prisms on each cusp were traced on to transparent acetate paper and transferred to an image analyser, where computer programs developed by Galai (Migdal Haemek, Israel) were used to calculate the mean prism area for each cusp. The centres of some adjacent prisms were marked with ink so that some contiguous triangles were delineated by them, and the three sides of each triangle (designated $d, x$ and $y$ ) were then measured in the image analyser. The average values obtained for the three linear measurements $(d, x$, and $y)$ were used to calculate the average ameloblastic cross-sectional secretory area (ASA) and the estimated prism density (EPD) for that specific region (Fig. 1). The linear measurements and the calculation of the prism spacing followed the methods developed by Fosse $(1968 \mathrm{a}-\mathrm{e})$. 


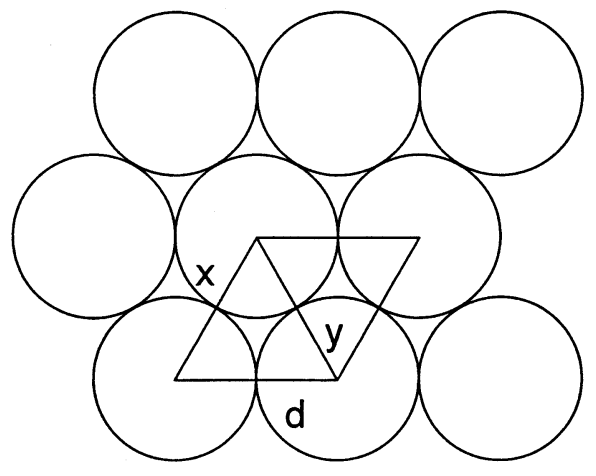

Fig. 1. Enamel prism-packing model to calculate the ameloblast secretory area and estimated prism density; see text for the sources and formula of these calculations.

Estimated prism density (number of prisms per $\mathrm{mm}^{2}$ ) was calculated using the following formula (Grine et al., 1987):

$$
\mathrm{EPD}=\frac{10^{6}}{1 / 2 Z^{2}(\sqrt{3})},
$$

where EPD is the number of circles per $\mathrm{mm}^{2}$ (see Fig. 1) and $Z$ is a given distance in $\mu \mathrm{m}$ between the centres of any two adjacent prisms.

Ameloblast secretory area was calculated in accordance with the following formula (Grine et al., 1987):

$A S A=\frac{1 / 2 \sqrt{4 d^{2} y^{2}-\left(d^{2}+y^{2}-x^{2}\right)^{2}}}{d}$.

The variables - ameloblast secretory area, estimated prism density and prism area - were determined for the mesiobuccal and distal cusps of permanent molars at various stages of development.
Boundaries of pattern 1 prisms (organised in rows, with complete boundaries, separated by interprismatic substance) were clearly defined on the photographs. For pattern 3 prisms (also arranged in parallel rows but with incomplete boundaries), the incomplete boundary was arbitrarily defined as the straight line joining the edges of the prism boundary with two prisms alternating and immediately inferior to it in the row (horseshoe-shaped; after Maas, 1994). Measurement error was caused by difficulty in (a) aligning and locating the cuspal area to be photographed and (b) defining the prism area. The error was estimated by repositioning the stubs in the microscope and rephotographing the surface of each cusp after an interval of some days. From this second set of photographs, new tracings were made of prism boundaries for each cusp and prism area measured and compared with those obtained for the first data-set. The combined error averaged $3 \%$.

\section{Results}

The mesiobuccal crown height ranged from 3.22 to $7.05 \mathrm{~mm}$. Fig. 2 shows the association found between maximal diameters and crown heights. The two were correlated $\left(r^{2}=0.75\right)$. A closer look at the scatter plot indicated that the values fell into two clusters, with little or no increase in mesiodistal diameter for teeth with crown height above $5.5 \mathrm{~mm}$. This finding is consistent with current hypotheses of crown formation, which suggest that the occlusal surface completes apposition of enamel when the crown is approximately two-thirds complete (Smith et al., 1995). Thus, $5.5 \mathrm{~mm}$ crown height was used as the cut-off point for dividing the teeth into early and late stages of crown formation.

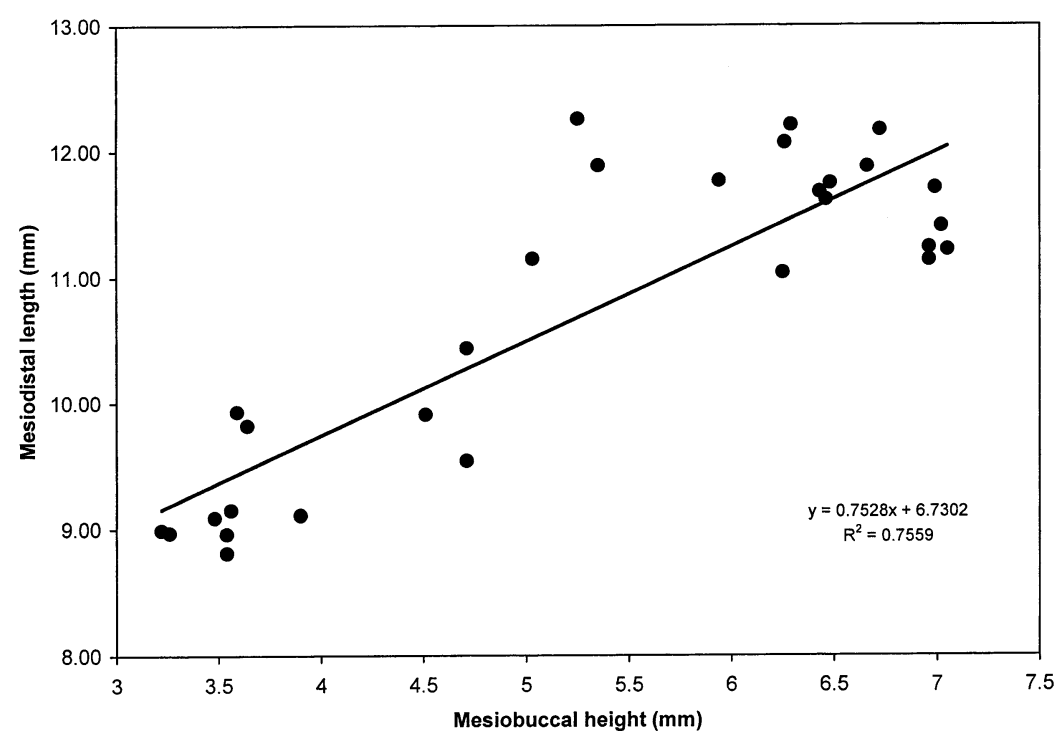

Fig. 2. The correlation between mesiodistal length and mesiobuccal crown height. 
Table 1

Comparison between prism areas of different cusps at different stages of development ${ }^{\mathrm{a}}$

\begin{tabular}{|c|c|c|c|c|c|c|}
\hline Pair & $N$ & Mean $\left(\mu \mathrm{m}^{2}\right)$ & S.D. & Minimum & Maximum & $P$ value \\
\hline MD - all & 25 & 44.61 & 14.54 & 22.72 & 85.48 & $0.00003 * * *$ \\
\hline $\mathrm{D}$ - all & 25 & 29.19 & 9.27 & 12.96 & 46.88 & \\
\hline MB - early & 13 & 44.41 & 17.72 & 22.72 & 85.48 & 0.472 \\
\hline MB - late & 12 & 44.68 & 10.90 & 27.02 & 64.12 & \\
\hline D - early & 12 & 24.98 & 9.31 & 12.96 & 37.83 & $0.014^{*}$ \\
\hline $\mathrm{D}$ - early & 12 & 24.98 & 9.31 & 12.96 & 37.83 & \\
\hline $\mathrm{MB}$ - late & 12 & 44.68 & 10.90 & 27.02 & 64.12 & $0.003 * *$ \\
\hline $\mathrm{D}$ - late & 13 & 33.07 & 7.65 & 20.80 & 46.88 & \\
\hline MB - early & 13 & 44.41 & 17.72 & 22.72 & 85.48 & $0.025^{*}$ \\
\hline $\mathrm{D}$ - late & 13 & 33.07 & 7.65 & 20.80 & 46.88 & \\
\hline
\end{tabular}

a *, $P<0.05 ; * *, P<0.01 ; * * *, P<0.001 ; \mathrm{MB}$, mesiobuccal; D, distal.

The intergroup analysis of prism variables centred primarily on one question. Were there any changes in prism area or density between the mesiobuccal and distal cusps or for early and late stages of development? This problem was tackled in various ways. First, $t$-tests were used in assessing differences between the means of each cusp and at different stages of development. Since there is always a risk of a type I error, Bonferroni's correction was applied (Miller, 1981). The Bonferroni test adjusts the observed significance level for the fact that multiple comparisons are made. In addition, as the non-parametric Kruskal-Wallis test is less sensitive, it is used for small samples with lack of normal distribution, so it was further reapplied to the data in order to test for differences among the cusps and stages of development. Statistical analyses were performed using SPSS 8.0 for Windows 95 .

\subsection{Prism area}

In order to study prism size and spacing we measured various prism variables in the mesiobuccal and distal cusps at different stages of development. Table 1 compares the mean prism areas of these cusps at different stages of development. Overall, the mean areas of prisms on the mesiobuccal cusp were significantly larger than those of the distal cusp at all stages of development $(P<0.001)$ and the differences in prism area between cusps were significant for each stage of development $(P<0.001$ for the early stage and $P<0.01$ for the late stage) (Table 1, Fig. 3). Prism area tended to increase between early and late stages of crown formation, whereas the differences were statistically significant for the distal cusp $(P<$
0.05) but they were not so for the mesiobuccal cusp (Table 1). The difference between the two cusps is exemplified in Fig. 4, which shows the scatter plot of prism area against crown height for both cusps. Linear regression analysis shows a significant if low correlation $\left(R^{2}=0.24\right)$ between crown height and prism area for the distal cusp, but none for the mesiobuccal cusp.
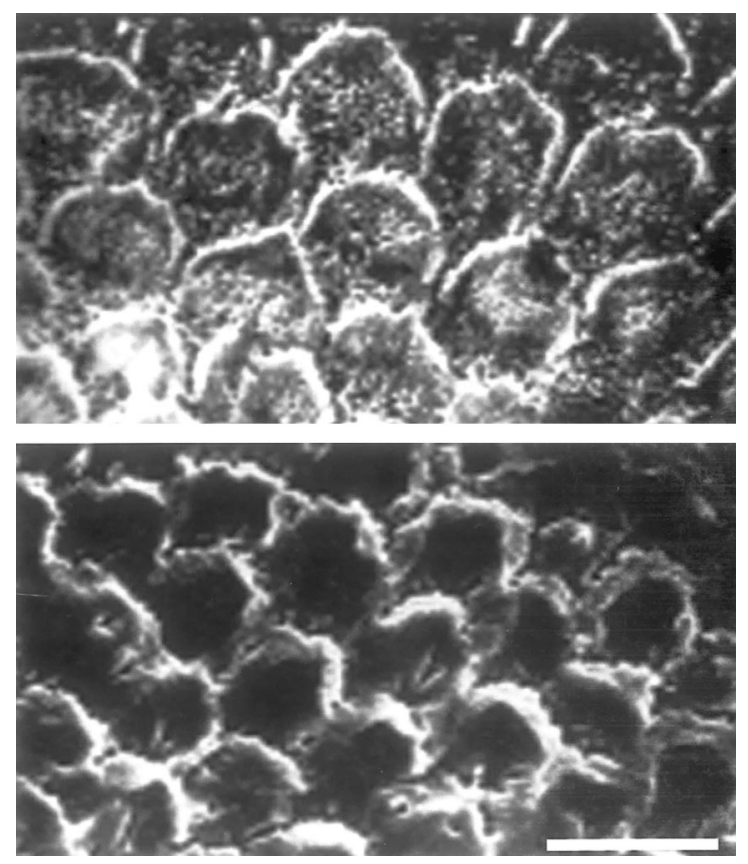

Fig. 3. Scanning electron-microscopic images of enamel illustrating prism-packing arrangement: (a) mesiobuccal cusp; (b) distal cusp. Bar $=20 \mu \mathrm{m}$. 


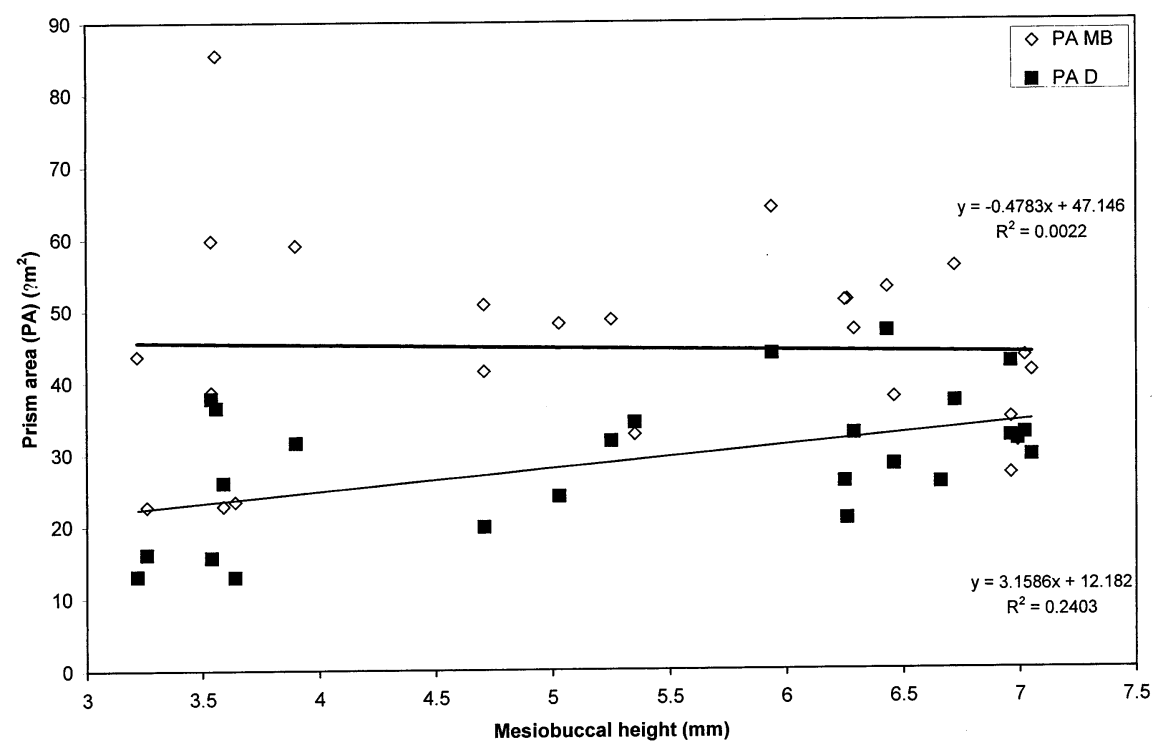

Fig. 4. The correlation between enamel prism area and mesiobuccal crown height.

Table 2

Comparison between ameloblast secretory areas (ASA) of different cusps at different stages of development ${ }^{\mathrm{a}}$

\begin{tabular}{|c|c|c|c|c|c|c|}
\hline Pair & $N$ & Mean $\left(\mu \mathrm{m}^{2}\right)$ & S.D. & Minimum & Maximum & $P$ value \\
\hline ASA MB - all & 28 & 65.36 & 22.33 & 27.68 & 121.25 & $0.004 * *$ \\
\hline ASA D - all & 22 & 51.04 & 14.58 & 29.97 & 77.97 & \\
\hline ASA MB - late & 14 & 64.05 & 16.24 & 40.59 & 101.80 & \\
\hline ASA D - early & 9 & 46.44 & 14.05 & 31.93 & 66.94 & 0.113 \\
\hline ASA D - early & 9 & 46.44 & 14.05 & 31.93 & 66.94 & \\
\hline ASA MB - late & 14 & 64.05 & 16.24 & 40.59 & 101.80 & $0.046^{*}$ \\
\hline ASA D - late & 13 & 54.23 & 14.62 & 29.97 & 77.97 & \\
\hline ASA MB - early & 14 & 66.04 & 27.76 & 27.68 & 121.25 & 0.089 \\
\hline ASA D - late & 13 & 54.23 & 14.62 & 29.97 & 77.97 & \\
\hline ASA MB - late & 14 & 64.05 & 16.24 & 40.59 & 101.80 & $0.005 * *$ \\
\hline
\end{tabular}

a * $P<0.05 ; * *, P<0.01 ; * * *, P<0.001 ; \mathrm{MB}$, mesiobuccal; D, distal.

\subsection{Ameloblast secretory area and prism density}

To further study prism variation we compared the ameloblast secretory areas of the mesiobuccal and distal cusps at various stages of development. Table 2 compares mean ameloblast secretory areas of both cusps at different stages of development. Mean ameloblast secretory areas on the mesiobuccal cusp were significantly larger than those for the distal cusp at all stages of development $(P<0.01$, all stages; $P<0.05$, early stage; $P<0.05$, late stage). In contrast, estimated prism den- sity was significantly smaller in the mesiobuccal cusp than the distal cusp at all stages of development $(P<$ 0.01 , all stages; $P<0.05$, early stage; $P<0.05$, late stage) (Table 3 ). These results were expected, as ameloblast secretory area and estimated prism density are inversely related.

Ameloblast secretory area on the distal cusp tended to increase between the early and late stage of development but the difference between stages was not significant. On the mesiobuccal cusp, ameloblast secretory area did not increase with crown height (Table 2). 


\section{Discussion}

Mature enamel has a complex three-dimensional structure (Osborn, 1981; Hillson, 1986). The enamel prism-packing patterns reflect the past history of the position and movements of ameloblasts, providing information about development and growth patterns of teeth (Boyde, 1990). Thus, the development of teeth is permanently recorded in their microstructure.

Previous studies have proposed a gradient in the cusp development of the first permanent molar, in which the mesial portion always develops ahead (in order and in form) of the distal portion (Butler, 1967c, 1968). It has been suggested that the mesial and distal portions of the crown are separate entities (Peretz et al., 1997), with the expression of the distal cusps being more variable than that of the mesial cusps (Saunders and Mayhall, 1982; Smith et al., 1987) and the outer enamel surface being more variable than the template of the tooth seen at the dentine-enamel junction (Kraus, 1952; Korenhof, 1960, 1982; Sakai, 1974; Smith et al., 1995).

Butler (1968) measured the intercusp distances of molar tooth germs at different stages of mineralisation and concluded that, in the lower DM2, the cusps tilted away from one another even before calcification; this was explained as a result of continued rapid mitosis at the base of the developing cusps immediately before bridging (Butler, 1967a,b). From these studies, Butler suggested that cell proliferation and furrow formation continue in adjacent regions, so that the relative height and distance between cusps may change and additional cusps and invaginations appear following the onset of calcification. More recently, Smith et al. (1997) demonstrated differences in angulation between cusps and proposed that their angulation reflects the spatial and temporal ordering of cell division and differentiation.
Although all five cusps unite at early stages of development there is continued apposition of enamel over the cusp tips and at the cervical margins (Kraus and Jordan, 1965). As seen in Fig. 2, there is an increase in mesiodistal length until crown height approaches 5.5 $\mathrm{mm}$.

Our results demonstrate a significant difference in prism area between mesiobuccal and distal cusps and between early and late stages of development within the first permanent lower molars. They agree with findings from a recent study of enamel microstructure using confocal laser scanning microscopy (Haydenblit et al., 1999), which showed that prism area and ameloblast secretory area are larger in the mesiobuccal than the distal cusp in modern permanent lower molars.

Prism size and spacing tend to increase close to the outer enamel surface (Chase, 1924; Fosse, 1964, 1968c; Kimura et al., 1977; Grine et al., 1986, 1987; Maas, 1994). Two possible factors are proposed as responsible for the increase in surface area from the dentineenamel junction to the enamel surface (Kimura et al., 1977): first, that enamel prisms increase their diameter while retaining a position perpendicular to the developing enamel surface; second, that enamel prisms retain a constant diameter while becoming angled relative to the developing enamel surface.

The fact that prisms reach the enamel surface in an oblique direction has been suggested to be an adaptation to the increased area (Radlanski et al., 1988). However, this notion has been questioned, as only the ameloblasts themselves are able to adapt to an increase in area and the enamel prisms are merely the passive tracks traced out by the ameloblasts (Risnes, 1998).

If the results obtained here are interpreted in line with hypotheses suggesting that increased thickness of

Table 3

Comparison between estimated prism densities (EPD) of different cusps at different stages of development ${ }^{\mathrm{a}}$

\begin{tabular}{lllrrr}
\hline Pair & $N$ & Mean $\left(\right.$ prisms per $\left.\mathrm{mm}^{2}\right)$ & S.D. & Minimum & Maximum \\
\hline EPD MB - all & 28 & 16335 & 4475 & 8247 & 24638 \\
EPD D - all & 23 & 20874 & 6414 & 12406 & 33371 \\
EPD MB - early & 14 & 16299 & 5011 & 8247 & 23897 \\
EPD MB - late & 14 & 16371 & 4060 & 9823 & 24638 \\
EPD D - early & 10 & 22107 & 6792 & 12406 & 31324 \\
EPD D - late & 13 & 19926 & 6211 & 12825 & 33371 \\
EPD MB - early & 14 & 16299 & 5011 & 8247 & 23897 \\
EPD D - early & 10 & 22107 & 6792 & 12406 & 31324 \\
EPD MB - late & 14 & 16371 & 4060 & 9823 & 24638 \\
EPD D - late & 13 & 19926 & 6211 & 12825 & 33371 \\
EPD MB - early & 14 & 16299 & 5011 & 8247 & 23897 \\
EPD D - late & 13 & 19926 & 6211 & 12825 & $33.018^{*}$ \\
EPD MB - late & 14 & 16371 & 4060 & 9823 & $0.048^{*}$ \\
EPD D - early & 10 & 22107 & 6792 & 12406 & 24638 \\
\end{tabular}

a *, $P<0.05 ; * *, P<0.01 ; * * *, P<0.001 ; \mathrm{MB}$, mesiobuccal; D, distal. 
enamel is associated with increased prism area and/or interprismatic distance (Risnes, 1998), then the apparent lack of significant change in mesiobuccal prism area between early and late stages of crown formation may be due to at least two reasons: first, continued enamel apposition in the later stages of crown development, with no increase in prism area or spacing between the prisms; second, early completion of enamel apposition on the mesiobuccal cusp such that it is completed even before the crown height reaches $5.5 \mathrm{~mm}$. The change observed in prism area in the distal cusp between early and late stages of crown formation is due to continued apposition of enamel, indicating a delay in enamel apposition in this cusp relative to the mesiobuccal cusp.

The difference in prism area between the mesiobuccal and distal cusps has two possible explanations: there is a marked difference in enamel thickness in the two cusps in both early and late stages of crown completion, owing to delay in the initiation and/or rate of enamel apposition in the distal cusp relative to the mesiobuccal cusp; or prism area in the distal cusp is consistently smaller than prism area of the mesiobuccal cusp, irrespective of enamel thickness.

The changes observed here in prism density and area between the earlier and later stages of crown formation are consistent and indicative of continued enamel apposition. We propose that the extent of the changes observed in the two cusps reflects differences in their developmental stage. That the mesiobuccal cusp showed little change throughout development suggests that enamel formation was nearly completed even in the youngest tooth germs studied (crown height $>5.5 \mathrm{~mm}$ ). In contrast, the highly significant changes recorded between early and late developing tooth germs suggest that enamel formation in the mesiobuccal cusp was still proceeding even in tooth germs with more than $5.5 \mathrm{~mm}$ crown height.

Further analyses of enamel thickness in different cusps of the tooth crown in humans may shed light on the importance of the relation between enamel prism size and spacing variables, thickness and cusp morphology. The use of scanning electron microscopy to compare enamel formation in the mesiobuccal and distal cusps may provide an additional tool for studying mesiodistal growth gradients in fossil tooth germs. We suggest that this non-destructive method may be of value in evolutionary studies for examining the overall pattern of enamel apposition, i.e. differences in timing between the development of different cusps of molar teeth. Furthermore, by integrating data on tooth size and enamel microstructure, it has an additional value complementary to current methods used for studying the ontogeny and phylogeny of teeth.

\section{Acknowledgements}

This work was supported by grants from the Israel Science Foundation founded by the Israel Academy of Sciences and Humanities. Rebeca Haydenblit is supported by a fellowship from the Hebrew University, Jerusalem. The research for this article was the subject of the late Tania Zeygerson's Master's thesis. Unfortunately Tania died suddenly before completing her thesis degree. This paper is dedicated to her memory.

\section{References}

Beynon, A.D., Dean, M.C., 1987. Crown formation time of a fossil hominid pre-molar tooth. Arch. Oral Biol. 32, 773780.

Beynon, A.D., Dean, M.C., 1988. Distinct dental development patterns in early fossil hominids. Nature 335, 509-514.

Beynon, A.D., Dean, M.C., Reid, D.J., 1991. On tick and thin enamel in hominoids. Am. J. Phys. Anthropol. 86, 295309.

Beynon, A.D., Wood, B.A., 1986. Variations in enamel thickness and structure in East African hominids. Am. J. Phys. Anthropol. 70, 177-193.

Boyde, A., 1990. Developmental interpretations of dental microstructure. In: Rousseau, C.J.D. (Ed.), Primate Life History and Evolution. Wiley-Liss, New York, USA, pp. 229-267.

Boyde, A., Martin, L., 1982. Enamel microstructure determination in hominoid and cercopithecoid primates. Anat. Embryol. 165, 193-212.

Boyde, A., Martin, L., 1984. The microstructure of primate dental enamel. In: Chivers, D.J., Wood, B.A., Bilsborough, A. (Eds.), Food Acquisition and Processing in Primates. Plenum Press, New York, USA, pp. 341-367.

Bromage, T.G., Dean, M.C., 1985. Re-evaluation at death of immature fossil hominids. Nature 317, 525-527.

Butler, P.M., 1956. The ontogeny of molar patterns. Biol. Rev. 31, 30-70.

Butler, P.M., 1967a. Comparison of the development of the second deciduous molar and first permanent molar. Arch. Oral Biol. 12, 1245-1260.

Butler, P.M., 1967b. Dental merism and dental development. J. Dent. Res. 46, 845-850.

Butler, P.M., 1967c. The prenatal development of human first upper permanent molar. Arch. Oral Biol. 12, 551-563.

Butler, P.M., 1968. Growth of the human second lower deciduous molar. Arch. Oral Biol. 13, 671-682.

Chase, S.W., 1924. The absence of supplementary prisms in human enamel. Anat. Rec. 28, 79-89.

Dean, M.C., Beynon, A.D., 1991. Histological reconstruction of crown formation times and initial root formation times in a modern human child. Am. J. Phys. Anthropol. 86, $215-228$.

Dean, M.C., Stringer, C.B., Bromage, T.G., 1986. Age at death of the Neanderthal child from Devil's Tower, Gibraltar and the implications for studies of general growth and development in Neanderthals. Am. J. Phys. Anthropol. 70, 301-309. 
Fosse, G., 1964. The number of prism bases on the inner and outer surface of the enamel mantle of human teeth. Acta Zool. Fennica 180, 1-76.

Fosse, G., 1968a. A quantitative analysis of the numerical density and the distributional pattern of prisms and ameloblasts in dental enamel tooth germs. III. The calculation of prism diameters and the number of prisms per unit area in dental enamel. Acta Odontol. Scand. 26, $315-336$.

Fosse, G., 1968b. A quantitative analysis of the numerical density and the distributional pattern of prisms and ameloblasts in dental enamel tooth germs. IV. The number of prisms per unit area on the outer surface of human permanent canines. Acta Odontol. Scand. 26, 410-433.

Fosse, G., 1968c. A quantitative analysis of the numerical density and the distributional pattern of prisms and ameloblasts in dental enamel tooth germs. V. Prism density and pattern on the outer and inner surface of the enamel mantle of canines. Acta Odontol. Scand. 26, $501-544$.

Fosse, G., 1968d. A quantitative analysis of the numerical density and the distributional pattern of prisms and ameloblasts in dental enamel tooth germs. VI. The vertical compression of the prism patterns on the outer enamel surface of human permanent teeth. Acta Odontol. Scand. 26, 545-572.

Fosse, G., 1968e. A quantitative analysis of the numerical density and the distributional pattern of prisms and ameloblasts in dental enamel tooth germs. VII. The numbers of cross-sectioned ameloblasts and prisms per unit area in tooth germs. Acta Odontol. Scand. 26, 573-603.

Grine, F.E., Fosse, G., Krause, D.W., Jungers, W.L., 1986. Analysis of enamel ultrastructure in archaeology: the identification of Ovis aries and Capra hircus dental remains. J. Arch. Sci. 13, 579-595.

Grine, F.E., Krause, D.W., Fosse, G., Jungers, W.L., 1987. Analysis of individual, intraspecific and interspecific variability in quantitative parameters of caprine tooth enamel structure. Acta Odontol. Scand. 45, 1-23.

Haydenblit, R., Podbilewicz, B, Smith, P., 1999. Evolution of human enamel growth analyzed by confocal microscopy. In: Mayhall, J., Heikkinen, T. (Eds.), Dental Morphology. Oulu University Press, Finland, pp. 228235.

Hillson, S., 1986. Teeth. Cambridge University Press, Cambridge.

Kimura, O., Dikes, E., Fearnhead, R.W., 1977. The relationship between the surface area of the enamel crowns of human teeth and that of the enamel-dentine junction. Arch. Oral Biol. 22, 677-683.

Kollar, E.J., 1983. Epithelial-mesenchymal Interactions in the Mammalian Integument. Tooth Development as a Model for Instructive Induction. Praeger Publishers, New York.

Korenhof, C.A.W., 1960. Morphogenetic aspects of the human upper molar. A comparative study of the enamel and dentine surfaces and their relationship to the crown patterns of fossil and recent primates. Acad. Proefschrift., Uitg. mij Neetlandia, Utrecht.
Korenhof, C.A.W., 1982. Evolutionary trends of the inner enamel anatomy of deciduous molars from Sangiran (Java, Indonesia). In: Kurten, B. (Ed.), Teeth: Form, Function and Evolution. Columbia University Press, New York, USA, pp. 350-355.

Kraus, B.S., 1952. Morphologic relationships between enamel and dentine surfaces of lower first molar teeth. J. Dent. Res. 31, 248-256.

Kraus, B.S., Jordan, R.E., 1965. The Human Dentition before Birth. Lea and Febiger, Philadelphia.

Maas, M.C., 1991. Enamel structure and microwear: an experimental study of the response of enamel to shearing force. Am. J. Phys. Anthropol. 85, 31-49.

Maas, M.C., 1994. Enamel microstructure in Lemuridae (Mammalia. Primates): assessment of variability. Am. J. Phys. Anthropol. 95, 221-241.

Miller, R.G., 1981. Simultaneous Statistical Inference. Springer, New York.

Osborn, J.W., 1981. Dental Anatomy and Embryology. Blackwell Scientific Publications, Oxford.

Osborn, J.W., 1990. A three dimensional model to describe the relation between prism direction parazone and diazone and the Hunter-Shreger bands in human tooth enamel. Arch. Oral Biol. 35, 869-878.

Peretz, B., Nevis, N., Smith, P., 1997. Morphometric variables of developing primary maxillary first molar crowns in humans. Arch. Oral Biol. 42, 423-427.

Radlanski, R.J., Jäger, A., Seidl, W., Steding, G., 1988. Durchmesser und anordnung der prismen im zahnschmelz. Eine morphologische untersuchung. Deutsche Zahnärztl. Z. 42, 1182-1192.

Ramirez Rozzi, F.V., 1993. Tooth development in East African Paranthropus. J. Hum. Evol. 24, 429-454.

Reid, D.J., Beynon, A.D., Ramirez Rozzi, F.V., 1998. Histological reconstruction of dental development in four individuals from medieval site in Picarde, France. J. Hum. Evol. 35, 463-477.

Risnes, S., 1998. Growth tracks in dental enamel. J. Hum. Evol. 35, 331-350.

Ruch, J.V., 1984. Tooth Morphogenesis and Differentiation. CRC Press, Boca Raton.

Sakai, T., 1974. Morphogenesis of the mammalian tooth with special reference to the cusp. Jap. J. Oral Biol. 16, 245-251.

Saunders, S.R., Mayhall, J.T., 1982. Developmental patterns of human morphological traits. Arch. Oral Biol. 27, 4549.

Shellis, R.P., 1984. Inter-relationships between growth and structure of enamel. In: Fearnhead, R.W., Suga, S. (Eds.), Tooth Enamel IV. Elsevier, Amsterdam, pp. 467471.

Shellis, R.P., 1998. Utilization of periodic markings in enamel to obtain information on tooth growth. J. Hum. Evol. 35, 387-400.

Slavkin, H.C., 1990. Molecular determinants of tooth development: a review. Curr. Rev. Oral Biol. 1, 1-16.

Smith, B.H., 1991. Dental development and the evolution of life history in Hominidae. Am. J. Phys. Anthropol. 86, 157-174. 
Smith, P., Koyoumidjisky-Kaye, E., Kalderon, W., Stern, D., 1987. Directionality of dental trait frequency between human second deciduous and first permanent molars. Arch. Oral Biol. 32, 5-9.

Smith, P., Peretz, B., Forte-Koren, R., 1995. The ontogeny of cusp morphology: the evidence from tooth germs. In: Radlanski, R.J., Renz, H. (Eds.), Proceedings of the Tenth International Symposium on Dental Morphology. "M" Marketing Services, Berlin, pp. 49-53.
Smith, P., Gomorri, J.M., Spitz, S., Becker, J., 1997. Model for the examination of evolutionary trends in tooth development. Am. J. Phys. Anthropol. 102, 283294.

Stern, D., Skobe, Z., 1985. Individual variation in enamel structure of human mandibular premolars. Am. J. Phys. Anthropol. 68, 201-213.

Thesleff, I., Hurmerinta, K., 1981. Tissue interactions in tooth development. Differentiation 18, 75-88. 